\title{
Climate Justice in the Palestinian Legal System: Analysis and Proposals for Reform
}

\author{
Mahmoud M. Dodeen ${ }^{1}$ \\ ${ }^{1}$ Assistant Professor, Faculty of Law and Public Administration, Birzeit University, Ramallah, Palestine \\ Correspondence: Mahmoud M. Dodeen. Tel: 97-05-9705-7078. E-mail: mdodeen@birzeit.edu
}

Received: August 27, 2017

Accepted: September 21, 2017

Online Published: October 28, 2017

doi:10.5539/ass.v13n11p83

URL: https://doi.org/10.5539/ass.v13n11p83

\begin{abstract}
This article examines the legal treatment of climate change matters in the Palestinian legislation. To assess the adequacy of current legislation, the article starts by looking at the amended Basic Law of 2003, as a temporary constitution. It then looks at laws relevant to various environmental elements and energy, and finally explores options for reform. It is found that several legal aspects of environment justice are already addressed by national legislation. Nonetheless, key legal and regulatory provisions on climate change concerns, in particular mitigation and adaptation, are still need to be developed. The article recommends appropriate legislative instruments to fill gaps in the overall existing legal framework, including the creation of a well-architected institutional framework, with clear jurisdiction and responsibilities, among competent authorities; to enhance national and sectoral strategies and plans for mitigation and adaptation to climate change. A national highly-transparent Environment and Climate Change Fund has also been suggested; to sustain the national ability in financing environmental and climate change activities.
\end{abstract}

Keywords: Adaptation, Clean Environment, Climate Change Law, Energy Law, Fundamental Rights, Legal Reform in Palestine

\section{Introduction}

Climate change and its effects continue to be one of the most prominent concerns of the international community. Countries have varying positions on how this issue should be tackled based on their own development and manufacturing interests, ambitions and their reliance on fossil fuel. International discussions have culminated in the creation of the United Nations Framework Convention on Climate Change (hereinafter UNFCCC) in 1992. Various protocols and conventions have emerged from the UNFCCC, such as the Kyoto Protocol (December 1997), the Doha amendment (December 2012), and most recently, the Paris Agreement (October 2016). The overall aim of these agreements is to reduce emissions from greenhouse gases to a level that does not adversely affect the ability of the natural ecosystems to adapt to climate change and to maintain repositories of these gases (sinks and reservoirs), including forests. These agreements facilitate research on measuring emission rates and the negative impacts that these emissions cause, as well as assessing the impacts of mitigation policies and plans that countries have developed. They also aims to strengthen awareness, training and cooperation programs, promote the development of environmentally friendly technologies, and improve the capacity of countries to adapt to climate change and the negative consequences associated with it.

These agreements also refer to special obligations where developed country Parties (Annex I parties) need to provide assistance to developing and least developed countries (non-Annex I parties) in order to enhance their capacities to adapt to the impacts of climate change. All parties, however, have common commitments to submit periodic reports on their climate activities for both mitigation and adaptation.

Literature emphasises that mitigation and adaptation are at the core of different legal systems addressing climate change (Ruhl, 2010, Hunt, \& Watkiss, 2011, Long \& Biber, 2014, Danielm, Jutta \& Lavanya, 2017). Emissions mitigation policies aim to slow the pace of climate change by reducing greenhouse gas emissions, while adaptation policies seek to address the negative impacts of climate change; to avoid or mitigate harm or to take advantage of the co-benefits that might arise (UNFCCC, 2007 \& Ruhl, 2010).

Several countries around the world have recently enacted special laws on climate change, ${ }^{1}$ while the majority of countries are in the process of reviewing their national legislation to accommodate climate change issues 
(Samuel, 2015 \& Nachmany, Fankhauser, Setzer \& Averchenkova, 2017). ${ }^{2}$ Currently these countries and some others deal with climate change through a set of general and diverse legislation. ${ }^{3}$

Adaptation can be considered as the most important issue for developing countries, including Palestine, because of their limited contribution to greenhouse gas emissions. In this regard, international climate change actors refer to key elements that national governments, particularly in developing countries, should take into account when preparing policies for effective adaptation to climate change. These are public participation, availability of information on decisions taken, appropriate institutional setup, planning tools and policy-making and resources. ${ }^{4}$

In Palestine, on April 5th 2010, the Palestinian Council of Ministers issued a decision to form the 21-member National Committee (the members were increased to twenty-seven in 2017) for Climate Change headed by the Environment Quality Authority (hereinafter EQA). The decision defined the main objectives of the Committee and based its preamble on the UNFCCC.

On March 29th 2016, the Council decided to nominate EQA as the National Designated Authority to the Green Climate Fund. This reflects the importance of the impact of climate change on sustainable development and the various other development sectors and so facilitates the implementation of national climate change plans by improving the capacities of national institutions. It also facilitates the process of communication with international funds (Environment Quality Authority, 2016).

A debate among some Palestinian scholars, specialists and officials has begun sometimes ago on how to regulate climate change issues. The Palestinian EQA, with donor support, has opened the floor for discussion. This paper comes to facilitate and participate in the ongoing national dialogue. The paper identifies and reviews the relevant articles in applicable laws to adequately tackle the subject matter and illustrate the overall picture of it; making it easier for stakeholders and decision-makers to choose the most appropriate legislative and regulatory interventions.

The paper aims to create an enabling legislative environment conducive to the implementation of national climate change policies. This should also assist in the implementation of the obligations of the State of Palestine as a result of its accession to the relevant conventions. The State of Palestine joined the UNFCCC on the 17th March 2016 and signed and ratified the Paris Agreement on the 22nd of April 2016. The Paris Convention entered into force on 4 November 2016.

\section{Constitutional Framework}

Climate change and human rights are broadly linked (Hall \& Weiss, 2012). Scholars have intensively discussed the threat of climate change on human rights. It is suggested that human rights law is better suited to guide policy-making, procedural responses and adaptation measures to climate change (Hall, 2014). Others suggest providing incentives for economically depressed communities to promote economic rights of individuals (Burkett, 2008). Human rights have also been linked to moral and ethical concerns; rich countries have been recommended to provide funding for adaptation and mitigation efforts to reduce harm in the poorest countries as a kind of compensation as long as harmful climate change practices cannot be avoided (Farber, 2012).

The amended Palestinian Basic Law of $2003^{5}$ considers a clean and balanced environment to be a human right (Article 33). The preservation and protection of the environment is considered as a national responsibility. In the same context, this law guarantees adherence to regional and international declarations and covenants that protect human rights (Article 10/2). This ensures that the Basic Law guarantees adherence to environmental conventions, including climate change. ${ }^{6}$ In this context, the UN Human Rights Council has recognised that environmental and climate changes directly and indirectly threaten the full and effective enjoyment of a range of human rights, including the rights to life, water and sanitation, food, health, housing, self-determination, culture and development (UN Human Rights Office of The High Commissioner [OHCHR], 2016). The OHCHR has released Key Messages on Human Rights and Climate Change (OHCHR, 2015). States are requested to put in place adequate polices in response to these massages for the sake of human rights protection. Accordingly, Palestine is constitutionally obliged to take effective measures to encounter climate change impacts.

Since natural disasters may be caused either by human action, by environmental factors or both, the Basic Law allows for the declaration of a state of emergency when there are various situations, including a threat to national security caused by a natural disaster (Articles 110-114). The President of the Palestinian Authority is granted the right to issue a presidential decree declaring a state of emergency for a period not exceeding thirty days. The decree must clearly state its purpose, the area covered and the time period. If the decree needs to be extended, the President then would be authorized to do so for an additional 30 days after the approval of two-thirds of the members of Legislative Council. This Council may not be dissolved during the state of emergency period 
(Article 110). The Council shall have the power to review the procedures and measures taken during the state of emergency at the first meeting following the declaration of the state of emergency or at the extension session, whichever is earlier, and to perform the appropriate interrogation in this regard.

\section{Environment Law}

The law No. (7) of 1999 concerning the environment indirectly deals with climate change through three topics: objective and general principles, the special conditions of aerobic environment and environmental impact assessment, and reference to relevant international treaties.

\subsection{Objective of the law and general principles}

The environment law acknowledges various concepts related to environment protection, including the definition of various environmental elements: pollution of the environment; air; water; pollutants and materials (including radiation); environmental damage; environmental impacts; pollution prevention as well as pollution and environmental disasters linked to extreme weather events associated with floods, drought, etc.; environmental monitoring and inspection; environmental degradation; nature reserves and environmental awareness(Article 1).

In general terms, the law came to achieve specific objectives including protection of the environment from pollution in all its forms; integration the foundations of environmental protection in economic and social development plans, and promotion the sustainable development of vital resources (Article 2). Consequently, the law aims to support the conservation of biological diversity, the protection of environmentally sensitive areas and the improvement of areas that are environmentally affected. The law also supports the collection and dissemination of environmental information and increasing public awareness of environmental problems.

In order to achieve these objectives, and to ensure implementation of the law, the law itself strengthened cooperation and coordination between EQA and other competent bodies in Palestine as well as with public, private and civil society institutions. ${ }^{7}$

\subsection{Special regulations of aerobic environment and environmental impact assessment}

The Environment Law obliges the EQA to set standards for regulating air pollution levels that may cause harm to public health, social welfare or the environment in cooperation with the competent authorities. All operating institutions are required to comply with these requirements. The use of machines, engines or vehicles resulting in exhaust that exceeds these standards is also prohibited. The prohibition is extended to increasing the level of radioactivity or concentration of radioactive materials emitted from any facility or any other practice above the permissible limits set by the competent authorities (Articles 19, $22 \& 27) .{ }^{8}$ This means that a legal foundation has been established in this law for regulating greenhouse gases. The US Supreme Court has insured this conclusion. ${ }^{9}$

The Law requires the EQA to work to limit the depletion of the ozone layer in accordance with the international treaties to which Palestine is committed (Article 24). This is done by taking appropriate measures with respect to the importation, production or use of any chemicals that cause harm to it. While these provisions do not refer specifically to climate change, there are substances that deplete the ozone layer which are also effective greenhouse gases, and vice versa. Moreover, climate change also has relation to ozone depletion. Therefore, there is a correlation and reciprocal relationship between the two concepts as is shown by various studies (World Meteorological Organization, 2011).

The third section of the law aims to regulate environmental impact assessments, licenses and inspection of facilities. It mainly focuses on the reduction of harmful effects to the environment, the prevention of environmental hazards as possible and the establishment of procedures to achieve this. EQA, with other competent authorities, are requested to develop the criteria for identifying projects and areas subject to environmental impact assessment studies and the relevant procedures needed to undertake this assessment. They are also recommended to identify an inclusive list of projects and activities that require prior environmental approval before being licensed by the competent authority. The EQA also needs to encourage licensors to switch to projects that use materials or processes that are less harmful to the environment.

\subsection{Referencing to relevant international treaties}

The Palestinian Environment Law explicitly considers the provisions and norms of International and Regional conventions, treaties as well as specialised international agencies of which Palestine is a party, a complementary part to the national Environment Law (Article 77). Provisions of any other laws related to the environment which are in effect in the Palestinian territory, are also considered complementary to this law, unless otherwise is provided. 
In addition, the importance of implementing the provisions of the Palestinian Environment Law and any other international conventions are also emphasised. The Law made it obligatory that EQA, in coordination with the local specialized agencies shall cooperate with the relevant agencies in the signatory countries to (i) exchange scientific and technical information, (ii) coordinate programs in the field of joint environmental research, (iii) set and implement joint cooperation programs to prevent or reduce environmental pollution and exchange various forms of assistance in this regard (Article 75).

We believe that considering and emphasising the importance of international treaties as part of the Palestinian Environmental Law of 1999 was the right decision to take. In addition, we argue that this approach is constitutionally legitimate due to the fact that the Palestinian Basic law, does not contain provisions on the legal value of commitments or obligations towards international treaties in national law and on how to enforce them within the Palestinian territories. It should, however, be noted that the Basic Law considers the right to a clean environment to be a human right which should be respected. Moreover, the abovementioned provisions were adopted by the Legislative Council as part of Environment Law. This means that these articles are considered as national law as long as they do not violate other principles and provisions of the Law.

\section{Other legislation complementary to environment law}

Greenhouse gas emissions are correlated to roughly every industry, including transportation agriculture, manufacturing, land and natural resources use. These sectors ought to be considered when designing the legal framework of environment and climate. Given the diverse aspects of the environment, various parties are required to work side by side with the EQA to protect various environmental resources and to mitigate and adapt to climate change. These include: Ministry of Agriculture, Palestinian Water Authority, the Palestinian Energy and Natural Resources Authority, Ministry of Transport, Department of Meteorology, Ministry of Local Government, Ministry of Finance and Planning, Ministry of National Economy and Ministry of Health among others. This section accordingly briefly describes key components of the most relevant laws to the subject matter to facilitate analysis and assessment of these in the subsequent section.

\subsection{Law-decrees on Water and Renewable Energy and Energy Efficiency}

The problem of adaptation to climate change is in many ways a water problem (Doremus, 2011), water resources are threatened by global warming. The Law-decree No. (14) of 2014 on water ${ }^{10}$ deals with pollution and contaminants, and defines its objective for the management and development of water resources in Palestine: increasing its availability, improving its quality as well as preserving the source and protecting it from pollution and leakage, while implementing the principles of integrated and sustainable management of water resources (Articles $2 \& 8$ ). This Law sets out the powers and responsibilities of the Water Authority, including the development of appropriate contingency plans and solutions for emergencies and crises; as well as to ensure uninterrupted supply of water services to citizens in coordination with the service providers and other relevant parties. The law also obliges the Water Authority to coordinate and cooperate with the competent authorities involved in the preparation of crisis management in the case of drought, or floods (droughts and floods are manifestations of climate change and considered as extreme weather events), epidemics transmitted through water or any general pollution (Article 50), regulating the use and management of industrial and agricultural resources that may contaminate water sources or supplies, and participate in environmental impact assessment committees for any water resources activity or supply system, and to prepare a list of the names of contaminants that require a license, as well as providing compensation for damages caused by the contaminants.

The Water Authority is required to monitor and inspect the water sources. Staff appointed by the Head of the Water Authority, have the power of the judicial authority to set cases of crimes and offenses prohibited by law (Articles 54 \& 55). ${ }^{11}$ The Law gives the power to the Water Authority, in coordination with the competent authorities including the EQA, to consider any area that contains a water source to be a protected area if the quality or quantity of water is at risk of pollution or depletion. The action above is also valid if the implementation of the water policy requires identifying certain areas as protected areas. However, this decision should be followed with a series of actions in order to ensure the availability of water supply, considering the available capacities and specific bylaw that has yet to be issued by the Council of Ministers (Article 52). ${ }^{12}$

The Law-decree No. (14) of 2015 on renewable energy and energy efficiency contributes positively to reducing the effects of climate change by encouraging alternative and clean energy sources. The law, however, does not mention the links between climate change and the reduction of greenhouse gases.

The Energy and Natural Resources Authority ${ }^{13}$ is responsible for implementing the objective of the law through enhancing the exploitation and development of renewable energy sources, ${ }^{14}$ energy efficiency and encouraging local manufacturing firms in the use of highly energy efficient equipment and renewable energy generating 
systems. The law requires all directly involved or legally responsible stakeholders from all sectors (private, public and civil society) to meet these objectives (Article 3). ${ }^{15}$

The law grants this Authority comprehensive powers to be exercised in cooperation with other jurisdictions. It also specifies the terms of reference for the Palestinian Centre for Energy and Environment Research and its relationship with other competent authorities including the Energy Authority itself (Articles 4 \& 8) ${ }^{16}$ The law also encourages the establishment of associations, committees, and trade unions which are specialized in the field of energy generation and services in order to activate, develop and grow investment in the renewable energy sector and improve energy efficiency in Palestine, in coordination with the Energy Authority (Article 9). Local councils, the Engineers Association and the Engineering Offices are required to promote and integrate energy conservation and renewable energy practices and their optimal use within design schemes (Article 17).

In order to encourage investment in renewable energy, the law exempts renewable energy and energy efficient equipment and devices from custom duties, and grants privileges to renewable power generation installations as set out in the Investment Promotion Law (Article 18). On the other hand, the decree does not address the question of emissions nor the reduction or adaptation to climate change impacts.

\subsection{Agriculture and Natural Resources Laws}

The amended Law No. (2) of 2003 on agriculture addresses the basic concepts related to the protection of the environment such as natural resources, agricultural capital, forestry and forest trees, and its sustainable use. The law also addresses desertification, which it defined as the decline in the production value of land uses due to climate change and humanitarian activities (Article 1).

The law defines the Ministry's powers in a broad manner, including: preparation of a sustainable agricultural development plan and programs; rational and optimal use of agricultural natural resources to ensure its sustainability; and the protection of animal and plant health; the control of animal, plant, epidemiological, infectious and common diseases (Article 2). All of these activities are required to be undertaken in cooperation with all relevant parties.

The law ensures the sustainable use of agricultural resources and calls for the formation of a specialized agricultural supportive institutions; an Agricultural Credit Bank and the establishment of a Palestinian Disaster Risk Reduction and Insurance Fund which is a farmers' compensation fund for natural disaster damage mostly associated with climate change. As such, a Law-decree was issued to create the risk prevention and agricultural insurance fund, No. 12 of 2013. Another Law-decree was issued, No. (8) for the year 2015, regarding the Palestinian Agricultural Credit Corporation. These two laws lack clear criteria for effective enforcement, and do not provide mechanisms for complains. Transparency and accountability rules are also not in place.

The law requested the Ministry of Agriculture to take measures to prevent the dumping of environmentally polluting waste, and the prohibition of encroachment on pastures (Articles $16 \& 21$ ). ${ }^{17}$ Nevertheless, the law neither recognises the use of technology in agriculture nor presents privileges for producers of environmentally friendly-products.

The Law No. (1) of 1999 on Natural Resources calls for the establishment of the General Directorate of Natural Resources (which is currently under the Ministry of National Economy) and defines its functions. ${ }^{18}$ The law encourages the exploration and use of natural resources after obtaining the necessary licenses from the public administration, in coordination with the competent authorities. These exploration activities include surveys, investigation, mineral extraction, processing and mining (Article 7).

Although Article (19) allows the Council of Ministers to prohibit research, prospecting or mining of any mineral or natural source of particular importance to the national economy or public policy, the law has failed to lay down the foundations and criteria for this. It also does not clarify the links between the exploitation of natural resources and the environmental impact it may has on climate change. It also does not mention the principle of efficient and equitable use of resources, thereby preserving environmental balance.

\subsection{Local Authorities and Industry Laws}

The Law No. (1) of 1997 on Local Authorities grants the Council of a local authority broad regulatory powers in order to issue regulations that are required to regulate the work of the local authority and secure its interests and needs (Article 15). The most relevant terms to the matter in question are: Taking precautions against floods, fires, natural disasters and others (which are linked to climate change) and taking precautions to cope with the risks of flood and flood hazards, to prevent fires, to monitor fuel and flammable materials, and to take precautions to respond to natural disasters and provide relief for those affected. Practically speaking, local authorities do not exercise these functions on systematic and regular manner due to lack of resources and overlap in jurisdiction 
with the Civil Defence Directorate and governors of the districts. Moreover, local authorities neither monitor health centres and hospitals, nor own shelters. Seemingly, local authorities are not going to adequately implement these powers due to the lack in planning and zoning polices in the whole country. These polices should have been formulated prior to the law endorsement.

The Law-decree No. (10) of 2011 on Industry grants the Minister of Economy the power to suspend the license of an industrial enterprise, or its operating license in whole or in part, following the recommendation of competent authorities if these prove that the industrial enterprise is manufacturing or producing products that pose a threat to the health and safety of the consumer or to the environment. The Minister of Economy is empowered to impose corrective measures on non-compliant enterprises, and the possibility to impose other punitive measures that may lead to the revocation of the license (Articles $9 \& 11$ ). A priority is given to award additional incentives, for industrial enterprises that: protect the environment, apply alternative and renewable energy in their activities, as well as enterprises that adopt and develop local technologies. Judicial officers enjoy the right to inspect enterprises to ensure that they are complying with the environmental laws Articles (18 \& 32). Risk associated with inaccessible or uneconomic resources, and responsive measures to climate change impacts are not dealt with in this law.

\section{Pros and cons of national legislation}

This section identifies the strengths and weaknesses of the Palestinian laws addressed in this article and suggests core aspects for legal reform.

\subsection{Advantages of the existing legislation}

Indeed several concerns of climate change matter are already demonstrated in national legal system. The most relevant millstones are:

- Acknowledgement that the right to a clean environment is a human right and the encouragement of the Basic Law to adhere to the charters and treaties governing human rights;

- The existence of legislation for various elements of the environment, such as for: water, agriculture, forestry, environment, electricity, renewable energy, local government, industry, etc.

- The existence of institutions operating in sectors related to environmental issues and climate change (Environment Quality Authority, Energy and Natural Resources Authority, Water Authority and other relevant ministries), as well as the requirements, set out in the legislation, for cooperation and coordination between these institutions;

- The Environment Law requires the determination of standards related to the regulation of air pollution in cooperation with the competent authorities. It obligates all establishments operating within these standards to adapt their processes to these requirements. As such, the Environment Law prohibits the use of machines, engines or vehicles that produce an exhaust that exceeds these standards;

- The environment law requires the EQA to act to reduce the depletion of the ozone layer in accordance with international treaties and to prohibit the increase in the level of radioactivity or concentrations of radioactive materials from installations and activities more than the permissible limits set by the competent Palestinian authorities;

- Recognition of international treaties and conventions as well as the decisions of international organizations working in the field of environment as an integral part of environment law;

- Encouragement of the exploitation and development of renewable energy sources; and

- The Council of Ministers' decision to form the National Climate Change Committee composed of members representing participation of all stakeholders.

\subsection{Deficiencies in the existing legislation}

The legislation tackled in this article lack regulation of significant matters necessary for capturing the climate change phenomenon and its implications. These shortcomings and gaps are identified subsequently.

- The provisions of the environment law have focused on the reduction of environmental pollution (mitigating the causes of climate change). However, the Law lacks clear and direct provisions that govern adaptation to climate change. Given the Palestinian situation, in particular its limited contribution to environmental pollution and greenhouse gas emissions aggregation compared to other countries (especially the industrial countries), adaptation remains the most important axes that must be worked on at an organizational and legislative level, while including the development of legislative policies that 
incentivise the mitigation and reduction of the causes of climate change. Furthermore, the current legislation fails to provide and monitor financial allocations for greenhouse gas mitigation actions and actions to adapt to the negative impacts of climate change, as well as the design of a clearly defined institutional framework with specific functions, powers and responsibilities (as a central body) for multi-jurisdictional coordination.

- The laws reviewed, call for collaboration and coordination amongst all relevant parties in order to enforce each of the relevant laws. Despite the significant importance of this approach, these legislations lack clear standards and procedures that demonstrate the nature and level of coordination and how it is to be implemented among the different parties. In addition, these laws lack clear accountability procedures.

- Existing in force laws, including the environment law, do not call for the need to develop a comprehensive national policy in order to mitigate and adapt to climate change across various sectors, including energy, agriculture, water, forestry, land use, transport and coastal areas in the Gaza Strip.

- Existing policies do not encourage national initiatives that aim to promote activities that focus on climate change adaptation and mitigation. This includes the lack of involving unprivileged and marginalised communities.

- Relevant laws do not request conducting of environmental impact assessment studies of potential activities and projects in order to evaluate their impacts on land use, forestry and water quality, the potential to increase of greenhouse gas emissions and adaptation. However, the environment law makes it compulsory to all projects to carry out an environmental impact assessment study.

- The law-decree, covering renewable energy, does not include sufficient incentives to encourage investing in renewable energy and energy efficiency (e.g., tax breaks, the allocation of land to new projects).

- The weakness of existing legislative framework to encourage private investment in public land-transportation in spite of its importance in reducing greenhouse gas emissions.

\subsection{The way forward}

It is necessary to address and tackle the weaknesses identified in current legislation as stated above. Particular requirements are:

- The establishment of an institutional framework that clearly sets out the responsibilities and powers needed to ensure the achievement of national and sectoral strategies and plans for mitigation and adaption to climate change. This framework should consist of three levels: coordination, technical knowledge and implementation. It should include the National Committee for Climate Change, General Directorate for Climate Change in EQA, Technical Units in ministries, public authorities, None Governmental Organizations and private stakeholders as appropriate. The presence of a Central Committee for Climate Change is crucial to ensure proper coordination and implementation of any proposed policies or legislative decrees. This committee should include relevant stakeholders (e.g., the Water Authority, the Energy and Natural Resources Authority, the Ministry of Transport and Communications and the Meteorological Department. The Ministry of Finance and Planning, the Ministry of National Economy, the Ministry of Health on the public sector and other relevant official institutions).

- The need to develop legislations further to improve their quality and effectiveness and ensure an enabling legal environment and promote relevant policies by consultation and communication with the stakeholders. This will enable a better understanding of the potential impacts of these legislations once issued.

- Encouragement of relevant stakeholders to exercise their legislative authorities, monitor their performance, and expedite the issuance of bylaws and secondary legislation, identified by laws as priority for implementation.

- Enhancement of adaptation and mitigation capacities with the relevant stakeholders, particularly climate change departments in ministries and relevant sectoral bodies, which need to be established in all relevant institutions. These capacities need to be enhanced for all sectors that could be affected by climate change.

- Incorporation of effective economic incentives and encouragement of investment opportunities in the various sectors that are affected by climate change such as health, industry, energy production and conservation, agriculture and forestry, biofuels, vehicle emission standards, water and sanitation, seas and marine life, etc. These incentives should also be available to NGOs, the academic community and technology providers. Examples of these incentives include direct subsidies, indirect subsidies through 
tax and customs exemptions, infrastructure facilities, State guarantees and support for private investments, soft loans and contracts, etc.

- Allocation of an annual budget from the government central budget for climate change activities and distribution across all relevant ministries and bodies.

- Establishment and operation of a national highly-transparent and technical Environment and Climate Change Fund to increase the national ability to finance environmental and climate change activities in order to achieve the goals of sustainable development in Palestine. This Fund should aim to fundraise, receive funding requests, evaluate funding requests, prioritise projects in accordance with approved strategies, coordinate support and monitor the implementation of projects in collaboration with other relevant stakeholders. Clear transparency and accountability rules should also be applied throughout the operation of the fund.

- Promotion of studies (e.g., survey, analytical surveying, documentation and monitoring) that address climate change issues, alternative and renewable energy resources, and in particular the enhancement of measuring, reporting and verification.

- Enhancing public awareness by launching communication, awareness and education campaigns as well as research and knowledge sharing and management projects.

- Raising awareness and providing training at both local and national levels. This includes capacity development for staff working in the field, and students in universities and schools.

- Promoting the increase of green areas by encouraging the cultivation of forest trees in private and public lands.

\subsection{Legislative options for the implementation of the proposed recommendations}

The question now is how can the decision maker accommodate the climate change issues into the Palestinian legal system? Indeed we do not envisage the incorporation of secondary legislation on climate change adaptation and mitigation into the current environment related laws. This is due to the absence of a clear and distinct link for such potential bylaws with the existing ordinary laws. In addition, it is obvious, pursuant to legislation hierarchy principle, that new environmental bylaws cannot be introduced if there is no basis within the current laws. Nonetheless, the shortcomings inherited in national legal system can be tackled through targeting one options from the following:

These limitation can be addressed by selecting one of the following three options:

1. Introducing a new standalone law that covers all aspects of climate change, previously discussed in this paper.

2. Amending current existing laws to incorporate new articles on climate change mitigation and adaptation. This could be done by introducing one law/decree that combines all amendments in one law.

3. Amending the environment law and finalising other bylaws that have not been issued yet (this includes emission limits as set out in the environment law, with modifications to them referring to emissions related to climate change). In addition, this amendment would require different stakeholders to work within their competence to draft new secondary legislation or bylaws as required by the proposed amendment to the environment law. Explicit articles on key matters are recommended to be introduced including; policy objectives, development of a climate change strategy, adaptation action plans and establishment of a system of periodic reporting to ensure the community remains informed.

Ideally, the first option is considered to be most appropriate due to its holistic approach. It also would be accurate, straightforward, uniform, and would have a clear set of procedures. This is because special laws prevail over general ones, and have priority in the implementation. Nevertheless, this option will not be the optimal scenario for the time being, otherwise it would entail a time-consuming and resource intensive approach; due to the lack of good understanding of the phenomenon and its implications among stakeholders and the society at large. In addition, there is a need to introduce policies to ensure its implementation and enforcement, as well as to evaluate its various effects, including its financial cost. Furthermore, potential conflicting articles between this law and the overall existing legislations are going to be in place. Such conflict would leave a state of overlap in jurisdictions among stakeholders working in the field.

The second option addresses the disadvantages of the first option. However, it requires various amendments to be made and therefore it would affect different laws. More importantly, this method requires multiple amendments that would perplex the implementation of the proposed organisational structure. The question that 
arises here is: which laws can be amended to incorporate the new recommended institutional set up?

The third option overcomes the challenges of the previous two options. However, it does not achieve all of the advantages of the first option. This option would demonstrate that the current environment law regulates the prevention of environmental pollution by adopting an approach that takes into consideration climate change. With regards to aspects that are not covered in the environment law, the latter refers these aspects to internationally agreed conventions. Therefore, future amendments will complement aspects that are not covered in this law and those that are relevant to climate change mitigation and, in particular, adaptation. Moreover, the amendment will include the addition of an organisational framework, approved by all relevant stakeholders. This amendment should also state the responsibilities, features and organisational procedures to collaborate amongst the different stakeholders. This would be followed by the establishment of a fund for the environment and climate change. The amendment may also include the provision of basic administrative, financial, supervisory, governance and accountability aspects associated with this fund. Alternatively, such requirements, pertaining to the fund, could be covered in a separate law. Amendments should also promote awareness, training and scientific research. Thus, the proposed amendments are limited but would meet the main purpose of this exercise. Finally, these amendments will include authority to all competent authorities, each within its sphere of jurisdiction, to prepare regulations and instructions for the general provisions that will be stated in the amendments.

\section{Conclusion}

The Palestinian legal system addresses some aspects of climate change concerns, while other key components are still absent. Since the environment law is considered the most relevant law to climate change, it is concluded that the third option discussed is the most appropriate for Palestine. Once the amendments have been entered into force for a certain period, and once the technical, human and financial capacities have been successfully achieved, a new standalone environment law covering climate change issues may be introduced. This approach would make its implementation easily achievable due to previous experiences of the law enforcement. Another advantage of this approach is the ability to benefit from the general set of provisions contained in the environment law and air-related decrees, environmental impact assessment, environmental permitting and licensing, monitoring and auditing, power awarded to specific stakeholders to deal with environmental crimes as well as referral of incidents to international conventions.

\section{Acknowledgements}

This paper has benefited from the author's reports and reviews submitted to the Palestine Environment Quality Authority as part of the "National Climate Change Capacity Development Program: Enhancing the Capacities of Palestinian Authority in Mainstreaming Environment and Climate Change". The author extends his gratitude to the UNDP and RICARDO company for energy and environment, for their generous support in finalising these reviews.

\section{References}

Burkett, M. (2008). Just solutions to climate change: A climate justice proposal for a domestic clean development mechanism. Buffalo Law Review, 56, 169- 243.

Danielm, B., Jutta, B., \& Lavanya, R. (2017). Introduction to international climate change law. International Climate Change Law, Oxford University Press. Retrieved from SSRN https://ssrn.com/abstract=3000009

Doremus, H. (2011). Climate change and evolution of property rights. UC Irvine Law Review, 1, 1091- 1124.

Environment Quality Authority, Ramallah. http://environment.pna.ps/ar/index.php?p=newsdetails\&id=163.

Farber, D. (2012). Climate Justice. Michigan Law Review, 110(6), 985-1002.

Grantham Research Institute on Climate Change and Environment and the London School of Economics, Climate change laws of the world. Retrieved from http://www.lse.ac.uk/GranthamInstitute/climate-change-laws-of-the-world/.

Hall, M., \& Weiss, D. (2012). Avoiding adaptation apartheid: Climate change adaptation and human rights law. Yale Journal of International Law, 37(2), 309-366.

Hall, M. (2014). Advancing Climate Justice and the Right to Health Through Procedural Rights. Health and Human Rights Journal, 16(1), 8-18.

Hunt, A., \& Watkiss, P., (2011). Climate change impacts and adaptation in cities: A review of the literature. Climatic Change, 104(1), 13-49.

Kyoto Protocol. (1997). http://unfccc.int/kyoto_protocol/items/2830.php. 
Long, E., \& Biber, E. (2014). The Wilderness act and climate change adaptation. Environmental Law, (44), 623-694.

Nachmany, M. (2016). The global climate legislation study- Summary of key trends, COP22, Marrakesh. Retrieved from http://www.lse.ac.uk/GranthamInstitute/legislation/

Nachmany, M., Fankhauser, S., Setzer J., \& Averchenkova A., (2017). Global trends in climate change legislation and litigation- 2017 update, The Grantham Research Institute on Climate Change and Environment. Retrieved from http://www.lse.ac.uk/GranthamInstitute/wp-content/uploads/2017/04/Globaltrends-in-climate-change-legislation-and-litigation-WEB.pdf

OHCHR. (November 27, 2015). Understanding human rights and climate change, to the 21st Conference of Parties to the UNFCCC. from http://www.ohchr.org/Documents/Issues/ClimateChange/COP21.pdf

Paris Agreement on Climate Change (2016). http://unfccc.int/paris_agreement/items/9485.php.

Ruhl, J. (2010). Climate change adaptation and the structural transformation of environmental law. Environmental Law, 40, 343. Retrieved from https://biotech.law.lsu.edu/climate/docs/ssrn-id1517374.pdf

Samuel, F. The 2015 Global climate legislation study: A review of climate change legislation in 99 countries: Summary for policy-makers, the Grantham Research Institute on Climate Change and Environment and the London School of Economics. Retrieved from http://eprints.lse.ac.uk/65347/

UN Human Rights Council, (January 2009). Report of the Office of the United Nations High Commissioner for Human Rights on the relationship between climate change and human rights. Retrieved from https://documents-dds-ny.un.org/doc/UNDOC/GEN/G09/103/44/PDF/G0910344.pdf?OpenElement

UN Human Rights Office of The High Commissioner [OHCHR], (2016). The rights of those disproportionately impacted by climate change, discussion paper. Retrieved from http://www.ohchr.org/Documents/Issues/ClimateChange/EM2016/DisproportionateImpacts.pdf

UNFCCC, Climate change: Impacts, vulnerabilities and adaptation in developing countries. (2007). Retrieved from https://unfccc.int/resource/docs/publications/impacts.pdf

United Nations Framework Convention on Climate Change (UNFCCC) (1992). https://unfccc.int/2860.php

World Meteorological Organization. (2011). Scientific assessment of ozone depletion: 2010, Global ozone research and monitoring project-report No. 52, 516, Geneva, Switzerland. Retrieved from https://www.wmo.int/pages/prog/arep/gaw/ozone_2010/documents/Ozone-Assessment-2010-complete.pdf.

The Basic Law of 2003. Palestine Gazette, special issue, 19 March 2003, p. 5.

Law No. (7) of 1999 concerning the Environment. Palestine Gazette, Issue No. 32, 29 February 2000. p. 38.

Law-decree No. (14) of 2014 on Water. Palestine Gazette, Issue No. 108, 15 July 2014, p. 13.

The Law No. (2) of 2003 on Agriculture. Palestine Gazette, Issue No. 47, 30 October 2003, p. 23.

Law No. (1) of 1999 on Natural Resources. Palestine Gazette, Issue No. 28, 13 March 1999, p. 10.

Law-decree No. (14) of 2015 on Renewable Energy and Energy Efficiency. Palestine Gazette, Issue No. 115,11 October 2015, p. 6.

Law No. (1) of 1997 on Local Authorities. Palestine Gazette, Issue No. 20, 29 November 1997, p. 5.

Law-decree No. (10) of 2011 on Industry. Palestine Gazette, Issue No. 92, 25 December 2001. P. 16.

\section{Notes}

Note 1. For example, UK, Victoria and Mexico. The United Kingdom Climate Change Act of 2008 established a committee on climate change to give advice to government on building a low-carbon economy and preparing for climate change. For more information see the Committee's website at https:/www.theccc.org.uk/. The Act aims to enable the UK to become a low-carbon economy and grants competent authorities powers to introduce measures necessary to achieve emissions reduction and design polices for mitigation and adaptation. See also Victorian Climate Change Act of 2017 at

https://www.climatechange.vic.gov.au/legislation/climate-change-act-2017; Climate Change Act of 2009 in Scotland at http://www.legislation.gov.uk/asp/2009/12/contents; and the Mexico's 2012 General Law on Climate 
Change

https://energypolicy.asu.edu/wp-content/uploads/2012/04/Mexico-2012-General-Law-on-Climate-Change-brief-s heet.pdf, last visited 25 July2017.

Note 2. The fourth annual Globe study (Samuel F.) looked at 98 countries in addition to the EU, and concluded that most of these countries had put into place or were establishing significant climate or energy legislation. See also, the global climate legislation study, summary of key trends 2016, COP22, Marrakesh, November 2016 at http://www.lse.ac.uk/GranthamInstitute/legislation/.

Note 3. Such as laws on Energy Efficiency, Clean and Renewable Energy, Clean Air, Clean Water and Conservation,; and Protection of Environment. See Nachmany M., et al. (2017). See also Grantham Research Institute on Climate Change and Environment and the London School of Economics, Climate Change Laws of the World, at http://www.lse.ac.uk/GranthamInstitute/climate-change-laws-of-the-world/.

Note 4. Disaster risk management should be integrated with the management of climate change. Together these must be dealt with in a way that promotes comprehensive and sustainable national development, creating a secure and stable national environment and guiding the development of policies, strategies and plans to reduce, mitigate and adapt to the main risk factors. This should be done in partnership with government agencies, the private sector, civil society institutions as well as scientific and academic institutions.

Note 5. The Palestinian Basic Law was drafted in 1994, established in 2002 and amended in 2003 and 2005, http://www.palestinianbasiclaw.org/.

Note 6. For more analysis one climate change and human rights see e.g., UN Human Rights Council, Report of the Office of the United Nations High Commissioner for Human Rights on the relationship between climate change and human rights. (January 2009), at https://documents-dds-ny.un.org/doc/UNDOC/GEN/G09/103/44/ PDF/G0910344.pdf?OpenElement; The International Council on Human Rights Policy, Climate Change and Human Rights: A Rough Guide. (2008). Versoix, Switzerland at http://www.ohchr.org/Documents/Issues/ ClimateChange/Submissions/136_report.pdf; Sabin Centre for Climate Change Law at Columbia Law School and United Nations Environment Programme, Climate Change and Human Rights, New York, 2015, at http://columbiaclimatelaw.com/files/2016/06/Burger-and-Wentz-2015-12-Climate-Change-and-Human-Rights.p df; and The Centre for International Environmental Law, Climate Change \& Human Rights: A Primer, retrieved from http://www.ciel.org/Publications/CC_HRE_23May11.pdf.

Note 7. See for example, Articles (4, 6-11, 16, 17, 19, 78). Moreover, Article (78) requires EQA to develop contingency plans to address environmental disasters, some of which are the result of climate change, in cooperation with the competent authorities.

Note 8. Article (23) of the Palestinian Environmental Law states that it is forbidden to deduct, treat or incinerate garbage and solid waste, that is only authorized in the sites designated for this purpose in compliance with the conditions determined by the Environment Quality Authority to ensure the protection of the environment.

Note 9. The Court ruled that the Clean Air Act authorizes Environmental Protection Agency (EPA) to regulate greenhouse gases. For analysis see Massachusetts et al. v. EPA et al. 549 U.S. 497, 2007 at https://supreme.justia.com/cases/federal/us/549/497/.

Note 11. This Law-decree replaced the Water Law No. (3) of 2002.

Note 12. The law calls for the formation of a council to regulate the water sector. The Water Authority is obliged to stop the extraction or supply of water if it is contaminated from either the source or the supply system. The Water Authority also has the power to shut down the source or the system if the pollution continues and should notify relevant authorities in order to address this issue and eliminate pollutants in an urgent manner (Article 51).

Note 13. Article (53) obliges anyone who polluted any water source or supply system to remove the pollutant at their expense. If they refuse or cannot do so, the Water Authority is required to remove the pollution and conduct the cleaning at the expense of the offender after being notified in writing no matter how much it costs, in accordance with the Public Funds Collection Act.

Note 14. This Authority was established under law No. (12) of 1995 on the establishment of the Palestinian Energy Authority to manage energy in all its forms (electricity, oil and gas derivatives, renewable energy elements, etc.). Article (3) defines the functions of this authority to be following among others: research and development for all types of renewable energy (e.g. solar, wind) and granting the necessary licenses for the generation and transmission of energy (Articles $3 \& 4$ ). 
Note 15. By means of increasing the contribution of renewable energy to the energy total in the energy balance, and achieving the objectives set out in the renewable energy strategy.

Note 16. Individuals and all parties that generate, distribute and consume all forms of energy certified manufacturers (both local and international) of energy generation equipment institutions, organisations and engineering firms that specialises in infrastructure design, sites and facilities that consumes any form of energy (public, private, public and private) Governmental educational organisations (in particular scientific research) Companies and NGOs.

Note 17. These tasks include: Commission studies, research projects and experiments to develop renewable energy sources, energy efficiency, environmental impact assessment studies (without making a reference to greenhouse gases). These projects could be delivered in collaboration with universities, research centres, ministries, relevant organisations. Another task is to review studies and energy efficiencies of existing systems, ask manufacturers to improve the efficiency of domestic and industrial electric equipment, raise the awareness with regards to renewable energy, organise training sessions, advise the energy authority to produce policies to increase energy efficiency across all sectors.

Note 18. Article (30) states that the launching of living beings which are modified through biotechnologies and which pose a danger to the health of humans or animals or bear a negative impact on the environment or which may threaten the agricultural biodiversity, shall be prohibited

Note 19. Article (3) of the Law states that: In coordination with other concerned authorities, the general administration shall have the following duties:

1. Preparing scientific studies and research pertaining to natural resources and shall issue directions for geological search and excavation for surface and ground resources;

2. Preparing geological maps and issuance of academic studies findings;

3. Geological exploration and search for natural resources;

4. Listing quantity and quality of natural resources; and

5. Supervising natural resources investment, according to systems and laws in force.

\section{Copyrights}

Copyright for this article is retained by the author(s), with first publication rights granted to the journal.

This is an open-access article distributed under the terms and conditions of the Creative Commons Attribution license (http://creativecommons.org/licenses/by/4.0/). 